\title{
THE USE OF THE FUZZY CLUSTERING ALGORITHM FOR PATTERN RECOGNITION IN FEED CONSUMPTION DATA OF PURE NEW ZEALAND WHITE RABBITS EXPOSED TO VARIED THERMAL CHALLENGES
}

\author{
Maria Alice Junqueira Gouvêa Silva \\ Federal University of Lavras (UFLA), Engineering Department, Campus, P. O. Box 3037, ZIP Code 37200-000, Lavras, \\ MG, Brazil \\ Corresponding author: malicejgsilva@gmail.com
}

\section{Tadayuki Yanagi Junior}

Federal University of Lavras (UFLA), Engineering Department, Campus, P. O. Box 3037, ZIP Code 37200-000, Lavras, MG, Brazil

\section{Raquel Silva de Moura}

Federal University of Lavras (UFLA), Zootechnics Department, Campus, P. O. Box 3037, ZIP Code 37200-000, Lavras, MG, Brazil

\section{Patrícia Ferreira Ponciano Ferraz}

Federal University of Lavras (UFLA), Engineering Department, Campus, P. O. Box 3037, ZIP Code 37200-000, Lavras, MG, Brazil

\section{Bruna Pontara Vilas Boas Ribeiro}

Federal University of Lavras (UFLA), Engineering Department, Campus, P. O. Box 3037, ZIP Code 37200-000, Lavras, MG, Brazil

\section{Marcelo Bahuti}

Federal University of Lavras (UFLA), Engineering Department, Campus, P. O. Box 3037, ZIP Code 37200-000, Lavras, MG, Brazil

\begin{abstract}
The performance of New Zealand White rabbits (NZW) is directly associated with to ambiancerelated factors because they present high sensitivity to high-temperature conditions. The objective of the present work was to use the Fuzzy C-Means (FCM) clustering algorithm for pattern recognition in daily feed consumption (CDR) of NZW rabbits exposed to different thermal challenges. The experiment was carried out in four air-conditioned wind tunnels installed in a laboratory. Twenty-four pure rabbits of the NZW breed aged 30 to 37 days were used. The experiment was carried out in two stages with a period of seven days each, and, at each stage, four dry bulb temperatures $\left(20^{\circ} \mathrm{C}, 24^{\circ} \mathrm{C}, 28^{\circ} \mathrm{C}\right.$ and $\left.32^{\circ} \mathrm{C}\right)$ were tested from the 30th day of the rabbits' life. Data on CDR (kilo, $\mathrm{kg} \mathrm{day}^{-1}$ ) were obtained by weighing the quantities supplied and the leftovers obtained daily from each rabbit in each treatment. Afterward, the Fuzzy C-Means algorithm (FCM) was used to classify the results. Also, to validate the analysis, the validation indexes were applied to indicate in which quantities of clusters the best partition results were obtained for this database. Thus, FCM cluster analysis was set up as a methodology capable of providing information on the thermal comfort of NZB rabbits in a precise and non-invasive way, which could assist the producer in decision-making.
\end{abstract}

Index terms: Fuzzy C-Means, rabbit breeding, thermal environment.

Received: June, 14, 2019 - Accepted: January 14, 2020.

\section{INTRODUCTION}

The New Zealand White (NZW) rabbit is a homeothermic mammal of European origin and is characterized as a highly prolific animal, very sociable and of nocturnal habits (Ferreira et al., 2012). In addition, according to Ferreira et al. (2012), it is considered an 
animal with great aptitude for meat and skin production.

In Brazil, the consumption of NZW rabbit meat is still small compared to the consumption of other countries such as in Asia (Bonamigo et al., 2017). However, rabbit breeding is an activity that presents great growth potential, mainly in family farming since it is possible to produce high-quality meat with high-quality skin and minimal investment (Motta, 2017).

The rabbits' performance is directly related to the factors related to the environment since these animals present high sensitivity to the environmental conditions, especially regarding high temperatures (Resende et al., 2012).

The environmental factors that most influence the welfare and, consequently, the rabbits' health, reproduction, and performance are primarily represented by the dry bulb temperature $\left(\mathrm{t}_{\mathrm{db}},{ }^{\circ} \mathrm{C}\right)$ and relative humidity ( $\mathrm{RH}, \%$ ) (Zeferino et al., 2011).

According to Jaruche et al. (2012), in order to achieve a good zootechnical performance, NZW rabbits over 30 days old should be exposed to an ideal $t_{\mathrm{db}^{\prime}}$ between 15 and $20 \mathrm{C}$ and $\mathrm{RH}$ between 60 and 70\% (Ferreira et al., 2012) because, when the animals are exposed to the intense heat condition, it immediately occurs the reduction in feed consumption and, consequently, the reduction in weight gain in relation to those kept in the thermoneutral zone (Zeferino et al., 2011).

Therefore, it is of the utmost importance that NZW rabbits kept in confined space are exposed to minimum thermal environmental factors daily variation to avoid the increase of metabolic and behavioral requirements in compensation to the thermal environmental changes (National Research Council, 1996).

Among the different methods that use computational intelligence as a tool to evaluate thermal comfort for animal husbandry, we highlight the Fuzzy C-Means (FCM) clustering method that is a fuzzy clustering method used to improve the results of complex questions related to data clustering (Leite et al., 2012).

The FCM clustering method is an interactive algorithm that starts with $c$ random values and, based on these values, associates each element with the value it has the shortest distance, forming $c$ groups (Bezdek et al., 1984).
Subsequently, the center of each formed group is calculated, and the elements are re-associated to the nearest center. In this way, calculations continue until the differences between the centers of the current step and the previous step are minimal. The defuzzification is given by the maximum, that is, in FCM, each object belongs to all classes, but with different degrees of membership, so that each object is allocated in the class where the degree of membership is higher (Bezdek et al., 1984).

In this context, this work aims to use the FCM clustering algorithm as a pattern recognition method in daily feed consumption data (CDR) of NZW rabbits exposed to chronic high-temperature challenges, observing if the classifier will be useful in the evaluation of comfort situations and/or heat stress caused by heat.

\section{MATERIAL AND METHODS}

The present work (protocol no 085/17) is in concordance with the ethical principles of animal experimentation, adopted by the Ethics Commission in the Use of Animals (Permanent Commissions / PRP-UFLA).

The experiment was conducted in four airconditioned wind tunnels made of galvanized steel sheets, metalon profiles, and PVC pipes, and steel plates installed inside an experimental room where the rabbits were exposed to chronic challenges due to high temperatures. The tunnels with closed-loop air circulation have valves for air renewal with the airflow being controlled manually through fans with speed control.

Twenty-four New Zealand White rabbits, 15 females and 9 males, aged between 30 and 37 days old, were used.

The experiment was carried out in two stages lasting seven days each. Thus, at each stage, 12 rabbits were randomly divided into four cages containing three animals each. These rabbits correspond to the three replicates of each treatment.

The rabbits were housed inside each tunnel in a galvanized wire cage divided into three equal parts of $0.08 \mathrm{~m}^{2}$ animal $^{-1}$ as recommended for the category of growing rabbits (Ferreira et al., 2012). 
Throughout the experimental period, three dry bulb temperatures $\left(t_{d b}\right)$ considered uncomfortable for weaned rabbits $\left(24^{\circ} \mathrm{C}\right.$, $28^{\circ} \mathrm{C}$ and $32^{\circ} \mathrm{C}$ ) as well as one $t_{d b}$ considered ideal for rearing weaned rabbits $\left(20^{\circ} \mathrm{C}\right)$ were tested. The temperature levels were selected considering the optimum temperature ranges recommended by the literature for weaned animals, whose range varies from 15 to $20^{\circ} \mathrm{C}$ (Zeferino et al., 2011), and had their upper limit extrapolated to generate conditions of heat discomfort.

In the two experimental stages, air humidity $(\mathrm{RH}, \%)$ and wind speed were maintained at $60 \%$ and at $0.2 \mathrm{~m} \mathrm{~s}^{-1}$ respectively, because they were considered within conditions that characterize thermal comfort (Ferreira et al., 2012).

The air humidification and the air heating inside the wind tunnels were obtained through electric heaters and humidifiers distributed in two activation stages.

The first stage allowed the temperature and $\mathrm{RH}$ in the environment within each airconditioned tunnel to reach a minimum reference value and the second stage is used to make the most accurate control of these variables.

For the control of the thermal environment inside the wind tunnels a datalogger type data acquisition, storage and control module (CR1000, Campbell Scientific) was used with data collection intervals of one minute. Also, the thermal environment $t_{d b}$ and $\mathrm{RH}$ variables were measured through temperature and $\mathrm{RH}$ sensors (HMP45C, Vaisala) with a minimum accuracy of $0.3^{\circ} \mathrm{C}$ and $1 \%$, respectively.

In Table 1 we can observe the average values of $t_{d b}$ and RH obtained at each experimental stage after programming the wind tunnels control system and having their values monitored throughout the experimental period.

In this way, it was possible to obtain numerous information about the thermal environment thus making it possible to infer about the quality of the control system of the air-conditioned wind tunnels, as well as to produce a quantity of data that allows knowing precisely the environment to which the rabbits were exposed.

Throughout the experimental period, the animals had free access to balanced commercial feed and drinking water. Also, the cages were cleaned to avoid the formation of gases such as ammonia which could interfere with the animals' performance.

Table 1: Mean values and standard deviations (in parentheses) of dry bulb temperature $\left(t_{d h}\right)$ and relative humidity $(\mathrm{RH})$ of each air treatment applied to the wind tunnels, with the experimental stage respective mean (seven experimental days).

\begin{tabular}{cccc}
\hline Treatment & $\begin{array}{c}\text { Experimental } \\
\text { stage }\end{array}$ & $\mathrm{t}_{\mathrm{dh}}\left({ }^{\circ} \mathrm{C}\right)$ & $\mathrm{RH}(\%)$ \\
\hline $20^{\circ} \mathrm{C}$ & 1 & $20.7(0.66)$ & $61(0.2)$ \\
& 2 & $20.3(0.02)$ & $60(0.1)$ \\
$24^{\circ} \mathrm{C}$ & 1 & $23.5(0.75)$ & $61(0.6)$ \\
& 2 & $24.0(0.09)$ & $60(0.1)$ \\
$28^{\circ} \mathrm{C}$ & 1 & $27.6(0.10)$ & $60(0.1)$ \\
& 2 & $27.9(0.09)$ & $60(0.1)$ \\
$32^{\circ} \mathrm{C}$ & 1 & $30.5(1.53)$ & $61(0.2)$ \\
& 2 & $31.7(0.12)$ & $59(1.4)$ \\
\hline
\end{tabular}

Daily feed intake $\left(\mathrm{kg}\right.$ day $\left.^{-1}\right)$ was obtained by weighing the quantities supplied and the leftovers obtained daily from each rabbit in each treatment.

Later, the Fuzzy C-Means (FCM) algorithm was used to find patterns in the feed consumption data of NZW rabbits exposed to heat stress.

Thus, the input variables of the FCM classifier are the dry bulb temperatures $\left(20,24,28\right.$ and $\left.32^{\circ} \mathrm{C}\right)$ and the feed intake throughout the experimental period. The output variable is the assessment of comfort situations and/or heat stress caused by CDR.

After applying the FCM clustering method, different amounts of clusters were obtained. Thus, the Xie-Beni validation indices, the partition index, and the partition coefficient were used to indicate in which amount of clusters the best partition values would be obtained. For the Xie-Beni method $(\mathrm{XB})$, the smaller the value of $\mathrm{XB}$ the more precise the partitioning (Xie and Beni, 1991) (Equation 1):

$$
X B=\frac{\sum_{i=1}^{c} \sum_{k=1}^{N}\left(\mu k_{i}\right)^{m}\left\|x_{k}-v_{i}\right\| 2}{N \frac{\min }{\forall k, i}\left\|x_{k}-v_{i}\right\| 2}
$$


wherein:

$\mathrm{N}$ is the data set;

is the degree association of the $\mathrm{k}^{\text {th }}$ sample in the $i^{\text {th }}$ cluster;

is a difamation constant;

,..., $\mathrm{N}$ is a sample;

is a cluster center;

$c$ is the number of clusters.

In turn, the Partition Index (SC) consists of the ratio of the sum of the capacity and separation of the clusters and thus, the smaller the value, the better the partition ratio (Equation 2):

$S C=\sum_{i=1}^{c} \frac{\sum_{k=1}^{N}\left(\mu k_{i}\right)^{m}\left\|x_{k}-v_{i}\right\| 2}{N_{i} \sum_{j=1}^{c}\left\|v_{j}-v_{i}\right\| 2}$

wherein:

$\mathrm{N}$ is the data set;

is the degree association of the $\mathrm{k}^{\text {th }}$ sample in the $\mathrm{i}^{\text {th }}$ cluster;

is a difamation constant;

,..., $\mathrm{N}$ is a sample;

is a cluster center;

is a cluster center with its former's;

$c$ is the number of clusters.

Therefore, SC is useful when comparing partitions with a similar number of clusters (Bensaid et al., 1996).

Finally, the Partition Coefficient (PC) is an index that measures the amount of overlap between clusters, that is, the higher the PC index, the better the partitioning (Bezdek et al., 1984). It is given by (Equation 3):

$P C=\frac{1}{N} \sum_{i=1}^{c} \sum_{k=1}^{N}\left(\mu k_{i}\right)^{2}$

wherein:

$\mathrm{N}$ is the data set;

$c$ is the number of clusters;

is the degree association of the $\mathrm{k}^{\text {th }}$ sample in the $\mathrm{i}^{\text {th }}$ cluster;

Therewith, CDR during heat stress is a linguistic description associated with the resulting clusters.

FCM clustering algorithms and $\mathrm{XB}, \mathrm{SC}$ and $P C$ validation indexes analysis were performed using the Matlab ${ }^{\circledR}$ Fuzzy Toolbox $^{\circledR}$ software version 7.13.0.564 (R2011b).

\section{RESULTS AND DISCUSSION}

The FCM algorithm is commonly used to find patterns in databases, and the number of clusters in the dataset is a key parameter for selecting the best results from the tested interactions (Mota et al., 2017).

Therefore, the $\mathrm{XB}, \mathrm{SC}$, and $\mathrm{PC}$ indices should be used to verify which final partition provided by the FCM clustering algorithm has the best performance level (Mota et al., 2017). Thus, minimum values found in $\mathrm{XB}$ and $\mathrm{SC}$ and maximum values found in $\mathrm{PC}$ define the best found partition to be used in the studied database.

The data was normalized in the range of 0 to 1 considering the proportions of the variables, and the $c$ set of random samples from the data set was considered as the initial means.

The results obtained using the FCM clustering algorithm and the results of the validation indexes $\mathrm{XB}, \mathrm{SC}$, and $\mathrm{PC}$ for their validation can be observed in Table 2:

Table 2: Validation of the FCM clustering algorithm through the validation indexes $\mathrm{XB}$, SC, and PC.

\begin{tabular}{ccccc}
\hline \multicolumn{5}{c}{ FCM } \\
Clusters & X & Validation & Validation time \\
& XB & SC & PC & (seconds) \\
\hline 2 & $\underline{1.1683}$ & 1.1932 & $\underline{0.8010}$ & $\underline{0.8460}$ \\
3 & 2.2910 & 0.9847 & 0.6866 & 0.8900 \\
4 & 7.3350 & 0.8385 & 0.6907 & 0.8825 \\
5 & 9.5910 & 0.8133 & 0.6733 & 0.8720 \\
6 & 7.5541 & 0.6381 & 0.6693 & 0.8615 \\
7 & 6.2789 & 0.4860 & 0.6776 & 0.9130 \\
8 & 8.4239 & $\underline{0.4529}$ & 0.6915 & 0.9295 \\
\hline
\end{tabular}

Table 2 shows that, according to each validation index, it was possible to determine the ideal partition values (clusters) and the time spent in the FCM classifier training to choose the best result from the interactions tested (dry bulb temperatures and CDR) during the study period.

When analyzing the obtained data, it is possible to notice that, for the indexes $\mathrm{XB}$ and 
PC, the ideal number of clusters for the clustering algorithm FCM would be of two clusters, whereas for SC the ideal number would be of eight clusters. Thus, it is observed that the ideal amount of partitions for the studied database would be two clusters.

When analyzing the FCM classifier in terms of precision, capacity, and processing time, it was observed that the best result and the shortest processing time of 0.8460 seconds were obtained with two clusters.

Figure 1 illustrates the clusters' decision limits for the FCM classifier according to the best clustering validation indexes found.

With Figure 1, it is possible to observe that the FCM classifier clustering allow the formation of overlapping spherical clustering (Mota et al., 2017).

Thus, Figure 1 also illustrates only the most representative attributes of daily feed intake data in NZW rabbits exposed to dry bulb temperatures $\left(\mathrm{t}_{\mathrm{db}}\right)$ of $20^{\circ} \mathrm{C}, 24^{\circ} \mathrm{C}, 28^{\circ} \mathrm{C}$ and $32^{\circ} \mathrm{C}$.

According to Ferreira et al. (2012), growing rabbits (30 to 50 days old) should receive feed at will, which varies from 0.080 to $0.130 \mathrm{~kg}$ day 1 according to age, production category, and thermal housing environment.

(a)

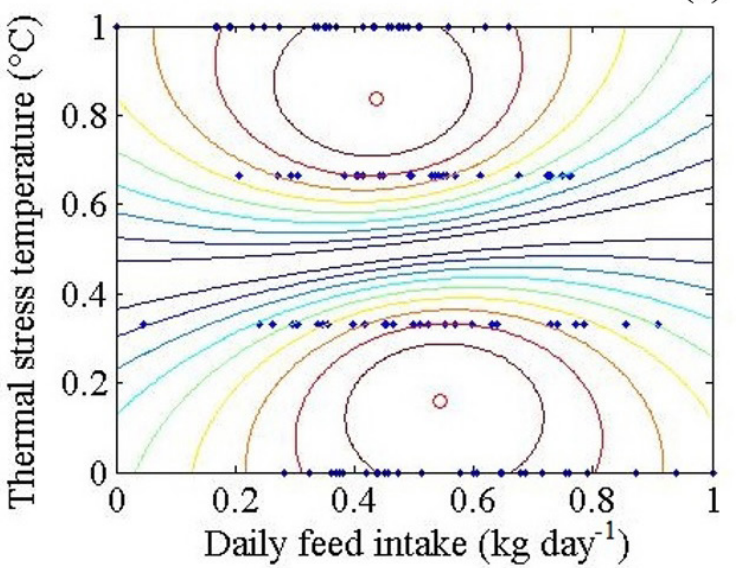

It is noted that the CDR (Figure 1a) is worse, with CDR values ranging from 0.026 to $0.066 \mathrm{~kg}$ day $^{-1}$ (range 0 to 0.5 ) when the temperature of thermal stress is in the range of above $0.5\left(t_{d b}\right.$ of 28 and $32^{\circ} \mathrm{C}$ ). Meanwhile, in the tbs of 20 and $24^{\circ} \mathrm{C}$ (temperature range of thermal stress of 0 to 0.5 ) it is possible to observe the increase in CDR (range 0.5 to 1.0 ) ranging from 0.035 to $0.078 \mathrm{~kg}$ day $^{-1}$.

Ferreira et al. (2017) evaluated the rabbits' behavioral parameters exposed to acute heat stress through camera shots every 5 minutes. The results obtained by the researchers were that rabbits exposed to heat $\left(\mathrm{t}_{\mathrm{db}}\right.$ of $\left.32^{\circ} \mathrm{C}\right)$ showed a decrease in feed consumption (CR) of $56.7 \%$ when compared to animals in comfort $\left(20^{\circ} \mathrm{C}\right)$. The authors also add that the reduction in CR possibly occurred due to the fact that heat stress animals tend to consume less feed to reduce diet-induced thermogenesis, also reducing the efficiency of metabolizable energy.

In this sense, in order to mitigate the harmful effects of heat stress, it is important to carry out more scientific studies for the development of specific technologies for hot climate regions producing information that guides the ambience activities of rabbit breeding (Ferreira et al., 2012).

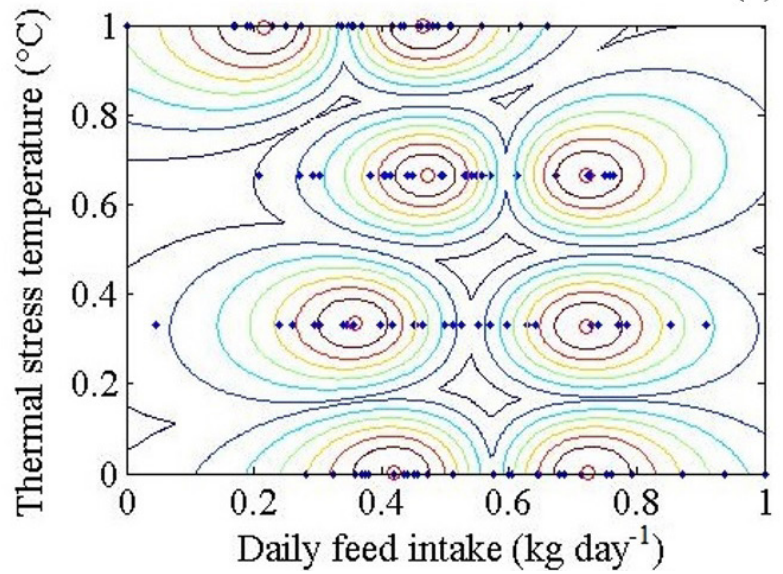

Figure 1: Best results found with the FCM classifier according to the validation indexes: (a) XB and PC with two clusters and (b) SC with eight clusters. The red dots are the centroids, and the blue dots are the data samples. 


\section{CONCLUSION}

The Fuzzy C-Means clustering method proved to be efficient in recognizing patterns in a data set containing the daily feed intake of rabbits that underwent heat stress conditions.

The validation given by Xie-Beni and Partition Coefficient indicated the existence of two clusters in the data analyzed and the Partition Index indicated the existence of eight clusters, considering that the validation time is decisive for obtaining better results.

Therefore, the use of the FCM clustering algorithm can be a valuable method to assist in the monitoring of situations in which rabbits may be in comfort and / or thermal discomfort.

\section{ACKNOWLEDGEMENTS}

The authors wish to thank (i) the Federal University of Lavras (UFLA) for providing the infrastructure to achieve this article, (ii) the FAPEMIG, CNPq and CAPES for financial support.

\section{REFERENCES}

BENSAID, A. et al. Validity-Guided (Re) Clustering with Applications to Image Segmentation. IEEE Trans. Fuzzy Syst, 4:112-123, 1996.

BEZDEK, J. C.; EHRLICH, R.; FULL, W. FCM: The Fuzzy c-means clustering algorithm. Computers \& Geosciences, 10(2-3):191-203, 1984.

BONAMIGO, A. et al. Produção da carne cunícula no brasil como alternativa sustentável. Revista em Agronegócio e Meio Ambiente, 10(4):1247-1270.

FERREIRA, R. A. et al. Estresse agudo por calor em coelhos. Revista Brasileira de Cunicultura, 12(1):4556, 2017.

FERREIRA, W. M. et al. Manual prático de cunicultura. 1 Edição. Bambuí, 2012. 75p.

JARUCHE, Y. G. et al. Efeito da densidade de alojamento sobre a homeostase térmica em coelhos em crescimento mantidos em diferentes temperaturas. Revista Brasileira de Cunicultura, 1(1):1-11, 2012.
LEITE, D.; COSTA, P.; GOMIDE, F. Evolving Granular Neural Networks from Fuzzy Data Streams. Neural Networks, 38(1):1-16, 2012.

MOTA, V. C. et al. Fuzzy clustering methods applied to the evaluation of compost bedded pack barns. In: 2017 IEEE International Conference on Fuzzy Systems (FUZZ-IEEE), Naples, p.1-6, 2017.

MOTTA, W. F. A. Cunicultura - Definições, curiosidades e observações. Boletim informativo Associação Científica Brasileira de Cunicultura (ACBC), 4(1):6-12, 2017.

NATIONAL RESEARCH COUNCIL. Guide for the care and use of laboratory animals. Washington, D. C. National Academy Press, 1996. 128p.

RESENDE, L. H. C; BORGES, J. F. P. M; SERAFIM, R. $\mathrm{S}$. Tosquia de coelhos como alternativa para melhorar o conforto térmico. FAZU em Revista, Uberaba, 9:8589, 2012.

XIE, X.; BENI, G. A Validity Measure for Fuzzy Clustering. IEEE Trans. Pattern Anal. Mach. Intell., 13(8):841-847, 1991.

ZEFERINO, C. P. et al. Genetic group $\times a m b i e n t$ temperature interaction effects on physiological responses and growth performance of rabbits. Livestock Science, 140(1):177-183, 2011. 